\title{
Electron microscopy of hepatitis B virus components in chronic active liver disease
}

\author{
R. DE VOS, M. B. RAY, AND V. J. DESMET \\ From the Laboratory of Histochemistry and Cytochemistry (Department 'Medische Navorsing'), \\ Academisch Ziekenhuis Sint Rafaël, University of Leuven, B-3000 Leuven, Belgium
}

SUMMARY Eighteen liver biopsy specimens from patients with hepatitis B surface antigen (HBsAg) positive chronic aggressive hepatitis were studied by electron microscopy. All cases were selected on the basis of positive liver cell membrane fluorescence for HBsAg on immunohistochemical investigation. Striking changes in the morphology of the liver cell membrane were observed in nearly all cases. Furthermore, a dual aspect of hepatitis B core antigen $(\mathrm{HBcAg})$ is described. $\mathrm{HBcAg}$ particles may occur as either 'naked' or 'cloudy' particles surrounded by semi electron dense material. The nature of the 'cloud' remains to be identified.

Hepatitis B viral components represent characteristic structures which can be revealed by electron microscopy. The hepatitis B core component has been described as $21-25 \mathrm{~nm}$ sized particles, located predominantly in the nuclei of the hepatocytes and to a lesser extent in their cytoplasm. The hepatitis B surface component was found to correspond to long filamentous or tubular structures located in the cisternae of the smooth endoplasmic reticulum (Huang, 1971; Stein et al., 1972; Huang et al., 1974).

Hepatitis B core antigen ( $\mathrm{HBcAg})$ as well as hepatitis B surface antigen (HBsAg) can also be demonstrated by immunohistochemical techniques (immunofluorescence, immunoperoxidase) on frozen and paraffin-embedded liver specimens (Gerber et al., 1974; Huang, 1975; Shikata, 1973; Yamada and Nakane, 1977).

Previous studies in this laboratory (Ray et al., 1976a, 1976b) and elsewhere (Gudat et al., 1975) have shown a differential distribution of HBsAg and $\mathrm{HBcAg}$ in various forms of hepatitis B. With these techniques, chronic aggressive (or active) hepatitis and active cirrhosis are characterised by an almost equal proportion of nuclear localisation of $\mathrm{HBcAg}$ together with cytoplasmic positivity for $\mathrm{HBsAg}$. Furthermore, expression of $\mathrm{HBsAg}$ in the liver cell membrane is a striking feature in these conditions (Ray et al., 1976b).

The present study was undertaken in order to obtain more detail on the ultrastructural counterpart

Received for publication 23 November 1978 of the immunohistochemical findings in chronic aggressive hepatitis with or without cirrhosis.

\section{Material and methods}

Eighteen needle biopsies of liver were performed on 18 patients clinically and histologically diagnosed as HBsAg positive chronic aggressive hepatitis. The sera of all these patients were positive for anti$\mathrm{HBcAg}$, and three of the nine determined samples were also positive for anti-HBsAg. The titre of DNA-polymerase was determined in only two serum samples and was rather high. e antigen was determined by the Ouchterlony technique in 11 cases; seven samples were negative and four were positive.

The cases were classified on the basis of previously described hepatic histology (De Groote et al., 1968; Bianchi et al., 1971) and immunofluorescence findings (Gudat et al., 1975; Ray et al., 1976b) as chronic aggressive hepatitis (14 cases) and active cirrhosis (4 cases).

The localisation of $\mathrm{HBsAg}$ and $\mathrm{HBcAg}$, as studied by immunofluorescence, showed a characteristic pattern: all biopsy specimens had a large number of positive nuclei for $\mathrm{HBcAg}$ while the $\mathrm{HBsAg}$ expression was mostly prominent in the liver cell membranes: 13 specimens showed a moderate to strong membrane staining in a variable percentage $(10-90 \%)$ of their hepatocytes; seven of these 13 biopsies showed a moderate to strong membrane staining in $90 \%$ of the hepatocytes; only five specimens revealed a rather faint membrane staining. 590 


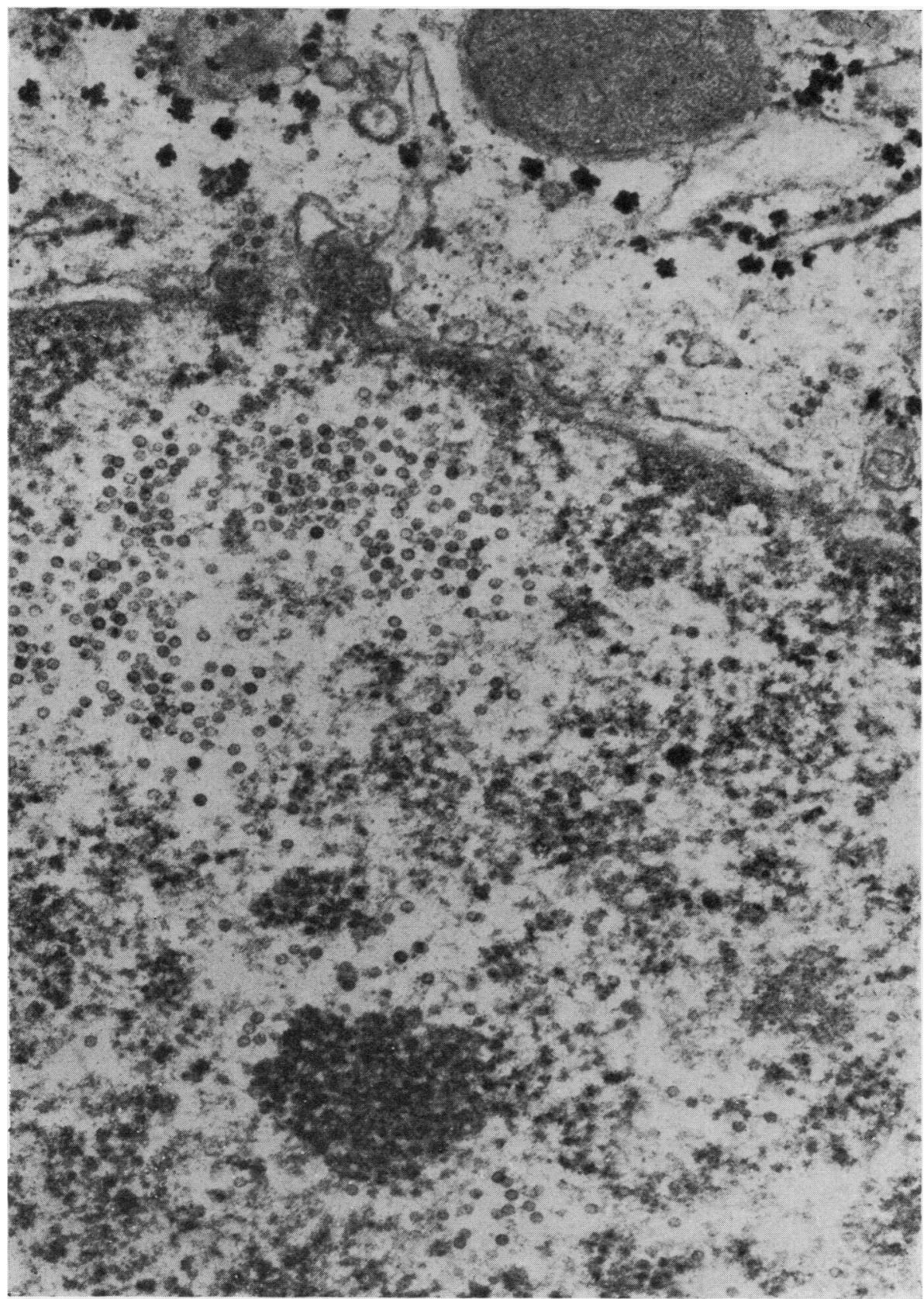

Fig. 1 Hepatocytic nucleus with naked HBcAg particles in the nucleus and in the nuclear pore $(\times 70000)$.

All the cytoplasm stained positively in a small number of hepatocytes in 15 specimens.

In all these biopsy specimens in vitro complement fixation was positive as studied with immunofluorescent techniques. In 12 cases, such in vitro complement fixation was found in the hepatocyte 


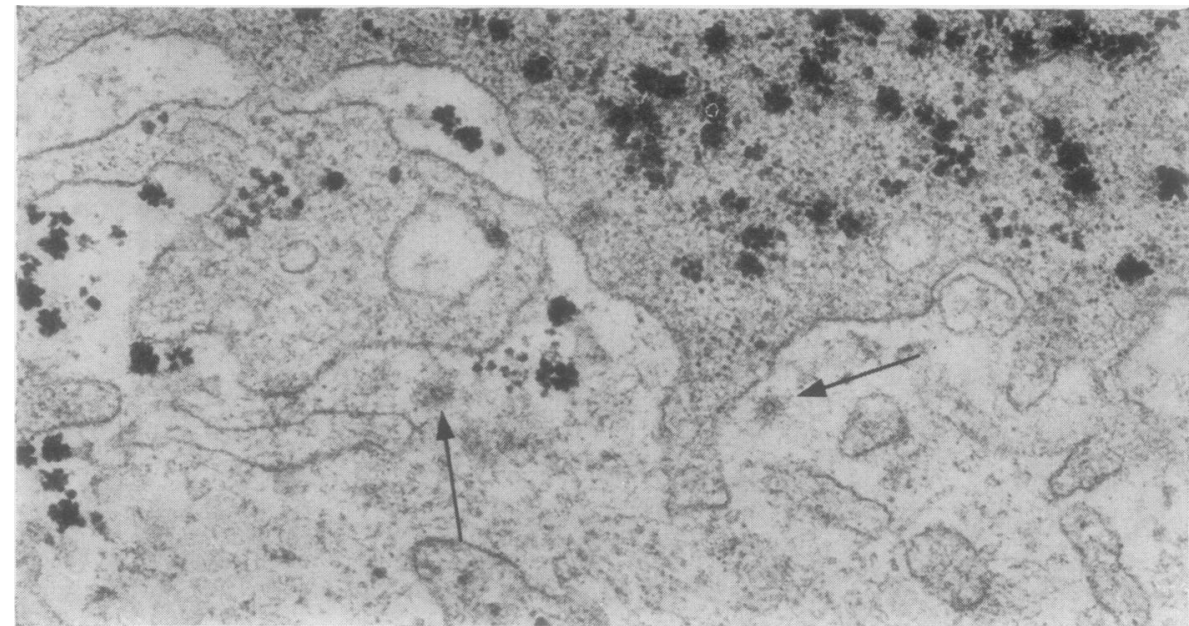

Fig. 2 Disse

space with two

HBcAg particles surrounded by $a$ narrow dark cloud of semi-dense fluffy material $(\longrightarrow)(x$ $56500)$.

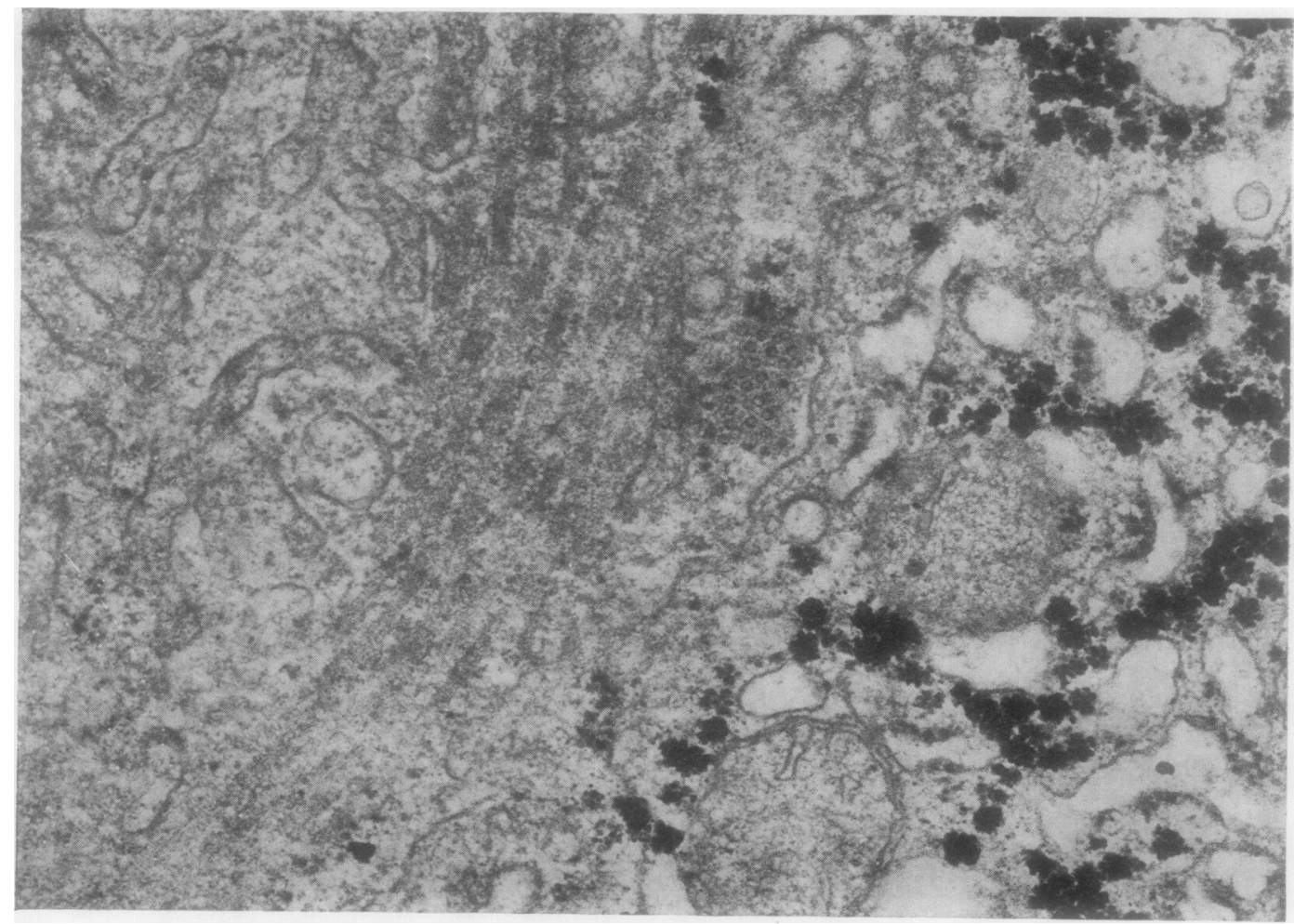

Fig. 3 Disse space with a group of 'clouded' HBcAg particles; collagen $(C)(\times 56500)$.

nuclei and in the cytoplasm, whereas in six cases it was restricted to the nuclei. On the other hand, 15 specimens showed nuclear fluorescence for immunoglobulin G (IgG) (Ray, 1978).
One part of the biopsy tissue was prepared for light microscopic diagnosis, a second part was prepared for immunofluorescent study, and a third part was prepared for electron microscopy. Thin 


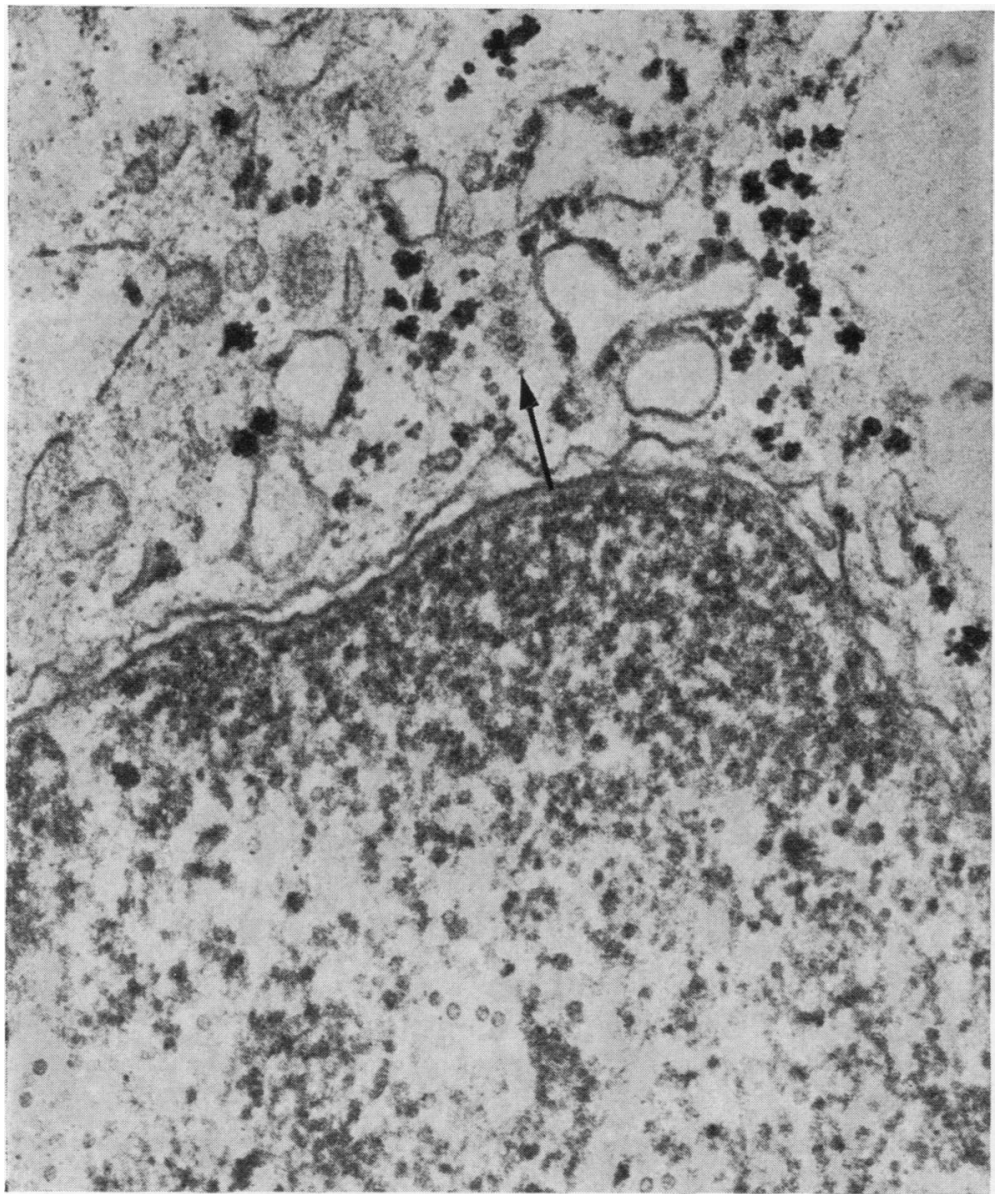

Fig. 4 Hepatocyte with 'clouded' HBCAg particles in the hyaloplasm $(\longrightarrow)(\times 70000)$.

blocks $(1 \times 1 \times 1 \mathrm{~mm})$ were immediately fixed by immersion for 1 hour in cold $\left(4^{\circ} \mathrm{C}\right) 2.5 \%$ glutaraldehyde phosphate buffer, $0 \cdot 1 \mathrm{M}, \mathrm{pH} 7 \cdot 2$, followed by a phosphate buffer rinse overnight. The specimens were postfixed in $1 \% \mathrm{OsO}_{4}$ in phosphate buffer, $0.1 \mathrm{M}, \mathrm{pH} 7 \cdot 2$, for 1 hour at $4^{\circ} \mathrm{C}$, dehydrated in graded alcohols, and embedded in Epon. Ultrathin sections were cut and stained with uranyl acetate followed by lead citrate and studied in a Zeiss EM10 electron microscope.

\section{Results}

In all 18 biopsy specimens a varying number of hepatocytes contained non-coated virus-like particles, 21 to $25 \mathrm{~nm}$ in size, localised in the nuclei; their number varied from nucleus to nucleus. As demonstrated in Fig. 1, such uncoated or naked core particles could occasionally be demonstrated in the nuclear pores.
These uncoated core particles were also found in the hyaloplasm in 16 specimens; in this location they were observed in any place, even near the cell periphery and in the pericanalicular ectoplasm.

In nine specimens core particles were found lying outside the hepatocytes; they appeared as single particles or in groups and were localised in the intercellular space or in the Disse space. These particles were always surrounded by a narrow, dark cloud of semi-dense fluffy material (Figs 2 and 3).

These clouded core particles were occasionally found in the cytoplasm of one or two hepatocytes in three specimens (Fig. 4).

In six biopsy specimens longitudinally cut tubules and cross-sectioned dots of HBsAg were found in the cisternae of the smooth endoplasmic reticulum (Fig. 5). In many positive cells the whole cytoplasm was filled with HBsAg containing SER; others showed these structures only in parts of their cytoplasm. 


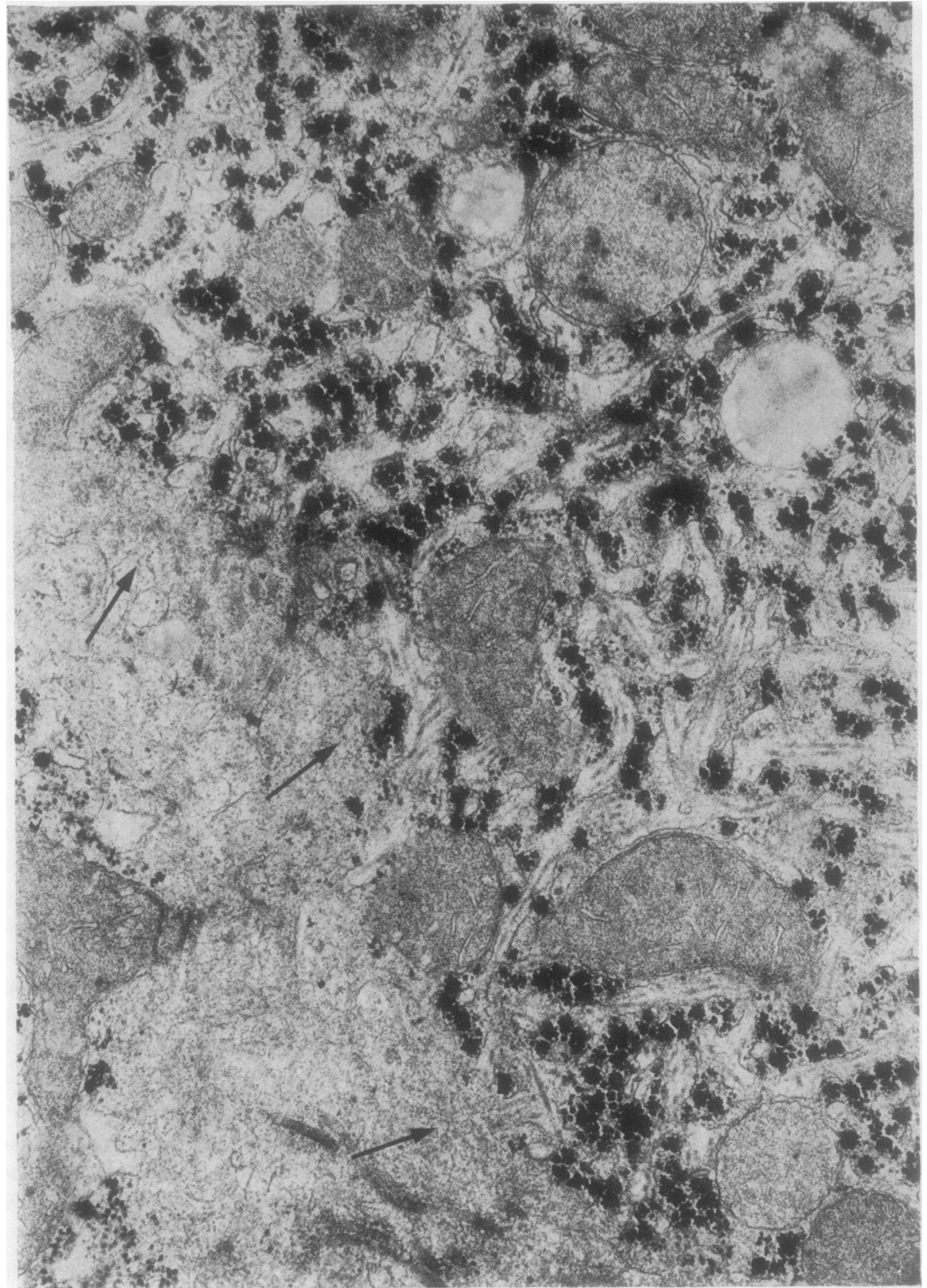

Fig. 5 Hepatocyte with longitudinally cut tubules and cross-sectioned dots of HBs Ag in the cisternae of the SER. The peripheral cell membrane is indistinct over a long segment (arrows) $(\longrightarrow)(\times 37000)$.

In seven specimens, mainly in hepatocytes containing HBsAg in their SER cisternae, the peripheral cell membrane was indistinct over a long segment or even seemed to have disappeared (Fig. 6). In other hepatocytes, the peripheral submembraneous area was thickened by the deposition of fluffy, filamentous material resembling the thin actin filaments described in numerous cell types (Allison, 1973; Marx, 1975; Phillips and Oda, 1974).

Furthermore, an amorphous material could be 


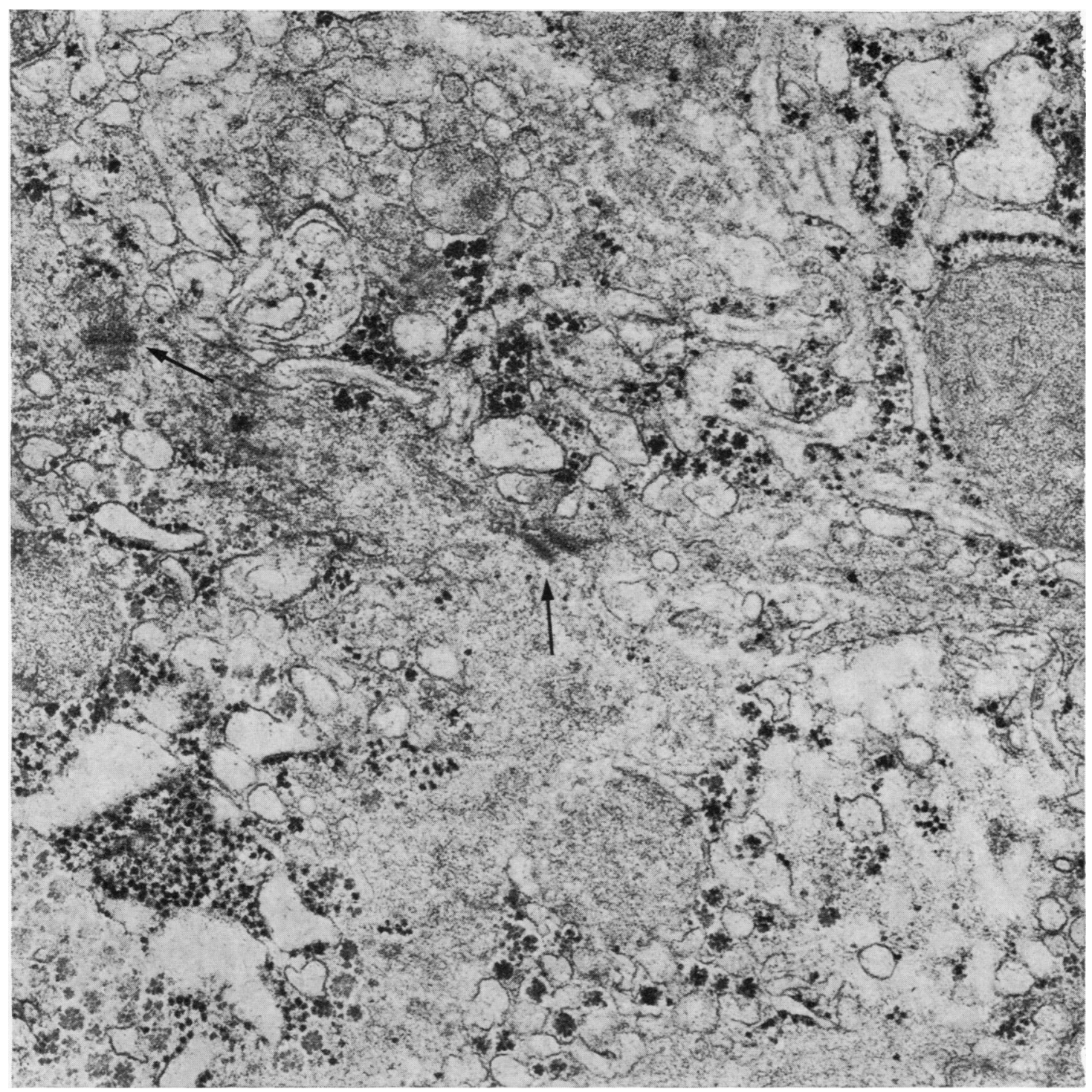

Fig. 6 Hepatocyte with indistinct peripheral cell membrane. The submembranous area is thickened by fluffy filamentous material. Two remnants of desmosomes can be seen $(\longrightarrow)(\times 48100)$.

detected in some slightly widened intercellular spaces between hepatocytes with increased microvilli in 11 specimens (Fig. 7). This was mainly the case in the biopsy specimens which showed a clearly delineated membrane positivity for HBsAg on immunofluorescence study.

In seven of the 18 specimens a single core particle was observed surrounded by a clear halo and a dark ring, $\pm 40 \mathrm{~nm}$ in size, located in the cisternae of the SER corresponding to the structures des- cribed as Dane particles (Dane et al., 1970) (Fig. 8). On two single occeasions a similar Dane particle was lying in a sinusoidal space.

With regard to liver cell morphology, the following striking feature was noted: cilia-like structures composed of protoplasmic extensions containing central microtubules were found on a single liver cell in three cases. These cilia-like structures were localised either at the canaliculus or at the sinusoidal pole. 


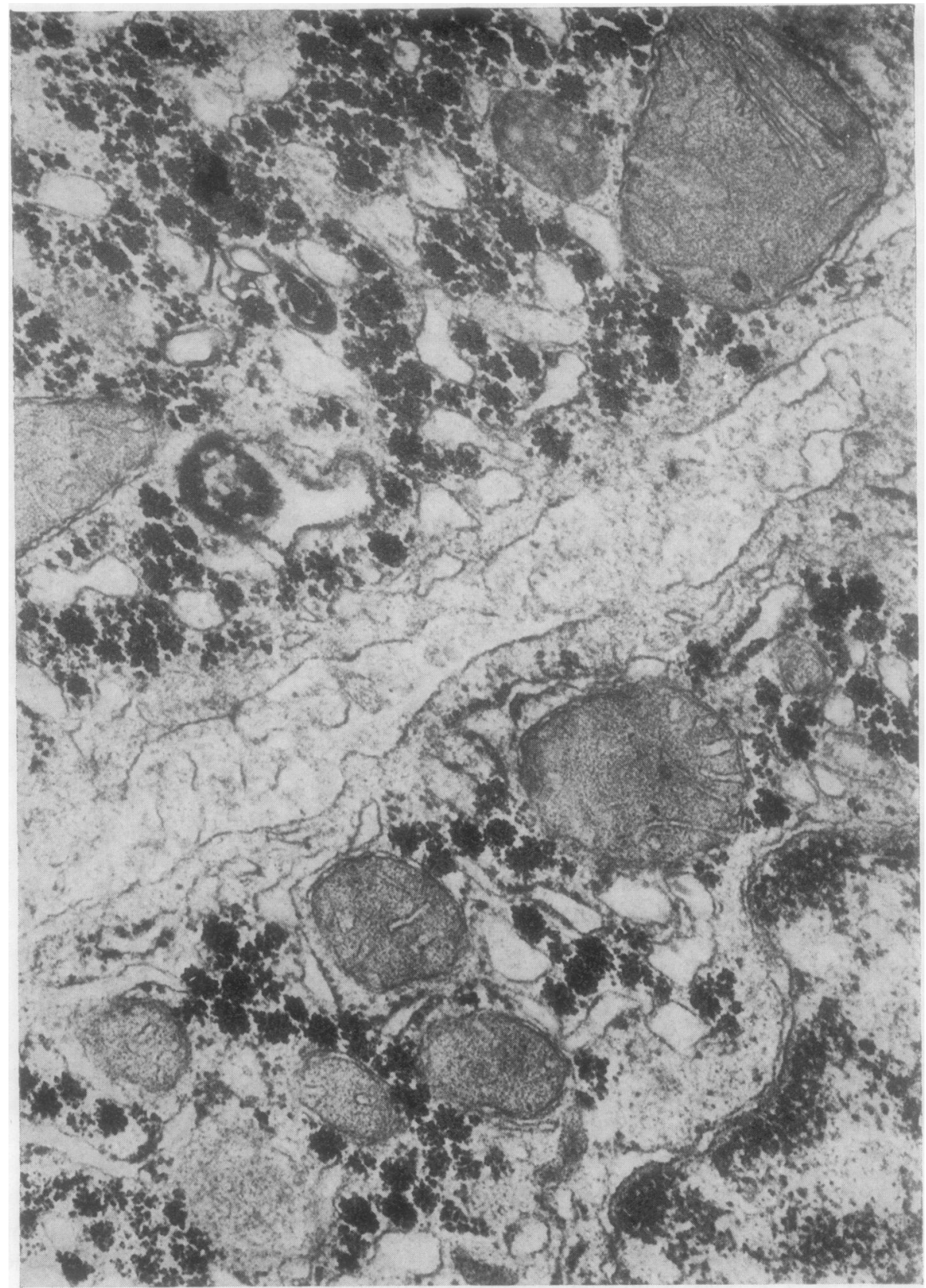

Fig. 7 Two neighbouring hepatocytes with widened intercellular space. Microvillous extensions and amorphous material can be seen $(\times 56500)$.

In spite of all these changes, it has to be mentioned that in each biopsy specimen a varying number of hepatocytes could be found with a normal morphological appearance.

\section{Discussion}

This investigation concerns a relatively homogeneous group of patients suffering from chronic aggressive 


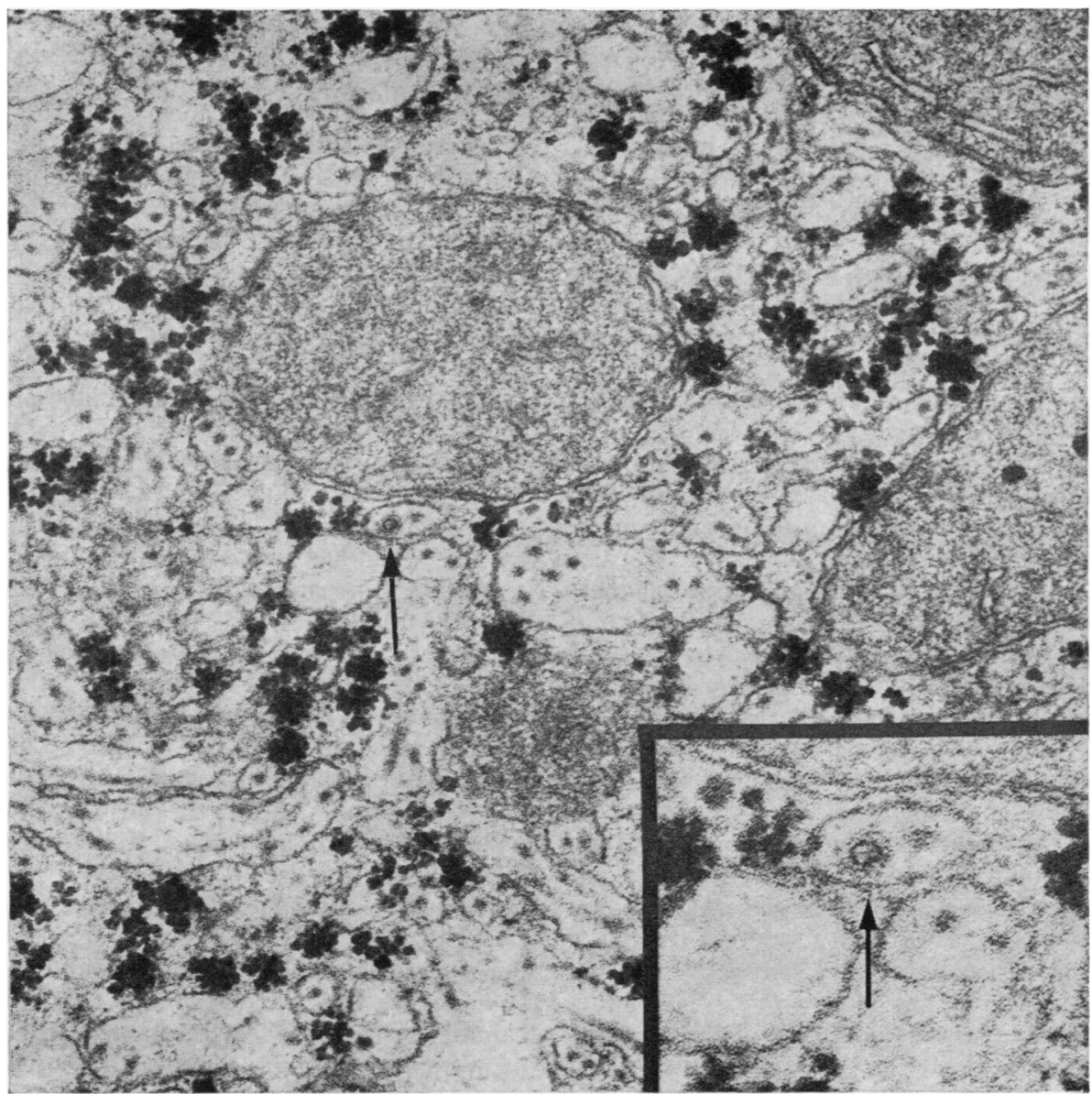

Fig. 8 Hepatocyte with HBsAg in the cisternae of the SER and a Dane particle $(\longrightarrow) \mathrm{M}$ (mitochondrion) $(\times 70000)$. Inset Dane particle $(\times 165000)$.

hepatitis, a minority of them being already in a stage of cirrhosis. Immunofluorescent investigation showed a nearly equal balance between the numbers of hepatocytes with nuclear $\mathrm{HBcAg}$ and cytoplasmic HBsAg. Characteristic for this selected group of cases was a strong fluorescence for HBsAg localised in the liver cell membranes. Although variation due to sampling unavoidably remains a problem, the results obtained are on the whole quite homogeneous. In general, they correspond to published reports on the ultrastructural aspects and localisation of HBcAg and HBsAg (Huang, 1971; Stein et al., 1972; Gerber et al., 1974; Huang et al., 1974; Yamada and Nakone, 1977).

Naked core particles were found mainly in the nucleus and to a smaller extent also in the hyaloplasm. They were found as single particles or in groups. Figure 1 demonstrates their passage through the nuclear pores, probably migrating from the nucleus to the cytoplasm.

A new finding is the occurrence of core particles surrounded by a narrow 'cloud' of semi electron dense material. Such 'clouded particles' are only rarely found in the hyaloplasm, occasionally near the nucleus, more often in the cell periphery. They are most often observed in the intercellular space or in the space of Disse. Actually all extracellular particles appeared to be of the 'clouded' type.

Their morphological appearance does not correspond to that of Dane particles. Pure morphological analysis does not allow identification of the nature of the 'cloud'.

Huang (1975) described aggregates of 'coated core particles' in the nucleus of hepatocytes from poorly processed biopsy specimens and from necropsyderived liver specimens, and interpreted the 'coat' as 
autologous anti-HBcAg. However, in the present study, the specimens were immediately and adequately fixed, as evidenced by satisfactory tissue preservation. Moreover, the 'clouded particles' in the present study are never observed as intranuclear aggregates but are found in extracellular sites andto a lesser degree-in the hyaloplasm of the liver cells.

The occurrence of $\mathrm{HBcAg}$ - anti $\mathrm{HBcAg}$ immune complexes in the nuclei and the cytoplasm of hepatocytes of chronic aggressive hepatitis patients has been proved in immunofluorescence by nuclear localisation of IgG and in vitro complement fixation (Nowoslawski et al., 1972; Sarno et al., 1975; Gerber et al., 1976; Rizzetto et al., 1976; Gudat et al., 1977). In vitro complement fixation was present in all specimens examined in the present study and nuclear fluorescence for IgG in 15 cases (Ray, 1978). The current interpretation of these observations is that autologous circulating anti$\mathrm{HBcAg}$ (IgG) may enter the hepatocyte, possibly due to altered permeability of the HBsAg containing cell membrane, and form complexes with $\mathbf{H B c A g}$ present in the nucleus. In view of this, a possible interpretation of the 'clouded particles' could be that they represent core particles complexed with anti-HBcAg. However, in vitro complement fixation and IgG are mainly demonstrable in the nucleus, precisely the site where in the present study no clouded particles have been found. Although a difference in tissue processing between immunofluorescent and electron microscopical techniques could be invoked to explain this apparent controversy, it seems necessary to consider further possibilities.

As an hypothesis, one could speculate whether the cloud could represent e antigen. This third antigenic component of the HBV was discovered recently (Magnius and Espmark, 1972; Magnius et al., 1975); it is usually associated with persistent viral infection in chronic hepatitis (Nielsen et al., 1974; Eleftheriou et al., 1975; El Sheikh et al., 1975), has been localised by immunofluorescent techniques in the hepatocytic cytoplasm by one author (Trepo et al., 1976), and is usually demonstrated in the blood of chronic hepatitis B patients. In this study, all patients had chronic aggressive hepatitis (a few of them complicated by cirrhosis). However, only four of the 11 serum samples tested were positive for e antigen, although the procedure used for determination of e antigen is known to be of low sensitivity. The lack of correlation between the presence of 'clouded' core particles in the biopsy specimen and of e antigen in the serum, together with the more recent demonstration of e antigen in hepatocytic nuclei (Arnold et al., 1977), speaks against an identity between the cloud and e antigen.

The finding of naked core particles in the nucleus, in the pores of the nuclear membrane, and, to some extent also, in the perinuclear region of the hyaloplasm suggests that the core particles are assembled in the nucleus (some components may come from a cytoplasmic synthesis site), leave the nucleus through the nuclear pores, and acquire their cloudy material in the cytoplasm (at least in some cells) or in the extracellular space. The finding of clouded core particles in extracellular sites clearly demonstrates that these structures can leave the liver cell for the bloodstream via an as yet unidentified pathway.

Although careful attention was paid to identified HBsAg in or near the liver cell membranes, no undeniable identification of $\mathrm{HBsAg}$ structural components was achieved in this location. A striking finding, however, was the impressive alteration of segments of the liver cell membrane in hepatocytes loaded with HBsAg: in these areas, the cell membrane became indistinct or even disappeared. These segments were too long and too frequent to be explained by oblique sectioning of the membrane. Equally intriguing is the occurrence of broad fibrillar areas beneath the cell membrane and the presence of amorphous and/or filamentous material in widened intercellular spaces. The submembranous microfilamentous areas are different from the microfilamentous hyperplasia described in cholestasis (Desmet, 1972; Gabbiani et al., 1975), in which case this phenomenon is restricted more to the pericanalicular zone. Pure morphology alone, however, cannot identify $\mathrm{HBsAg}$ in these altered liver cell membranes. Immuno-electron microscopy is required definitely to resolve this issue.

As mentioned in the literature, an occasional Dane particle could be found in an occasional liver cell, located inside the cisternae of the SER or in an extracellular site. The location of core particles in the hyaloplasm, and the presence of $\mathrm{HBsAg}$ and Dane particles in the cisternal lumina of the SER raise the question how the Dane particle is assembled.

Cilia-like cytoplasmic extensions on the canalicular and sinusoidal pole of the liver cell is a rare phenomenon which was previously described in a case of intrahepatic cholestasis (Byler disease) by De Vos et al. (1975). The significance of this liver cell alteration remains unknown, although it cannot be regarded any more as pathognomonic for the disease entity in which it was originally reported.

We are indebted to Dr G. De Groote for valuable help; we thank Mrs van Wetswinkel-Vanrykel for technical assistance, $\mathrm{Mr} \mathrm{M}$. Rooseleers for preparing the photographs, and Mrs M. VeulemansWeckx for typing the manuscript. 
This study was supported by a grant from the Fonds voor Wetenschappelijk Genneeskundig Onderzoek.

\section{References}

Allison, A. C. (1973). The role of microfilaments and microtubules in cell movement endocytosis and exocytosis. In Locomotion of Tissue Cells (Ciba Foundation Symposium, 14), p. 109. Elsevier, Amsterdam.

Arnold, W., Nielsen, J. O., Hardt, F., and Meyer zum Büschenfelde, K. H., (1977). Localisation of e-antigen in nuclei of hepatocytes in HBsAg-positive liver diseases. Gut, 18, 994-996.

Bianchi, L., De Groote, J., Desmet, V. J., Gedigk, P., Korb, G., Popper, H., Poulsen, H., Scheuer, P. J., Schmid, M., Thaler, H., and Wepler, W. (1971). Morphological criteria in viral hepatitis: review by an international group. Lancet, 1, 333-337.

Dane, D. S., Cameron, C. H., and Briggs, M. (1970). Virus-like particles in serum of patients with Australiaantigen-associated hepatitis. Lancet, 1, 695-698.

De Groote, J., Desmet, V. J., Gedigk, P., Korb, G., Popper, H., Poulsen, H., Scheuer, P. J., Schmid, M., Thaler, H., Uehlinger, T., and Wepler, W. (1968). A classification of chronic hepatitis. Lancet, 2, 626-628.

Desmet, V. J. (1972). Morphologic and histochemical aspects of cholestasis. In Progress in Liver Diseases IV, edited by $\mathbf{H}$. Popper and F. Schaffner, pp. 97-132. Grune and Stratton, New York.

De Vos, R., De Wolf-Peeters, C., Desmet, V., Eggermont, E., and Van Acker, K. (1975). Progressive intrahepatic cholestasis (Byler's disease): case report. Gut, 16, 943-950.

Eleftheriou, N., Thomas, H. C., Heathcote, J., and Sherlock, S. (1975). Incidence and clinical significance of e antigen and antibody in acute and chronic liver disease. Lancet, 2, 1171-1173.

El Sheikh, N., Woolf, I L., Galbraith, R. M., Eddleston, A. L. W. F., Dymock, I. W., and Williams, R. (1975). e antigen-antibody system as indicator of liver damage in patients with hepatitis B antigen. British Medical Journal, 4, 252-253.

Gabbiani, G., Montesano, R., Tuchweber, B., Salas, M., and Orci, L. (1975). Phalloidin-induced hyperplasia of actin filaments in rat hepatocytes. Laboratory Investigation, 33, 562-569.

Gerber, M. A., Hadziyannis, S., Vissoulis, C., Schaffner, F., Paronetto, F., and Popper, H. (1974). Electron microscopy and immunoelectronmicroscopy of cytoplasmic hepatitis B antigen in hepatocytes. American Journal of Pathology, 75, 489-502.

Gerber, M. A., Sarno, E., and Vernace, S. J. (1976). Immune complexes in hepatocytic nuclei of $\mathrm{HB} \mathbf{A g}$ positive chronic hepatitis. New England Journal of Medicine, 294, 922-925.

Gudat, F., Bianchi, L., Finch, M., Krey, G., and Endo, Y. (1977). Nuclear fluorescence of liver cells for IgG in viral hepatitis $B$ : significance and relation to hepatitis
B-core and anti-hepatitis B-core formation. Klinische Wochenschrift, 55, 329-336.

Gudat, F., Bianchi, L., Sonnabend, W., Thiel, G., Aenishaenslin, W., and Stalder, G. A. (1975). Pattern of core and surface expression in liver tissue reflects state of specific immune response in hepatitis $B$. Laboratory Investigation, 32, 1-9.

Huang, S. N. (1971). Hepatitis-associated antigen hepatitis: an electron microscopic study of virus-like particles in liver cells. American Journal of Pathology, 64, 483-500.

Huang, S. N. (1975). Immunohistochemical demonstration of hepatitis B core and surface antigens in paraffin sections. Laboratory Investigation, 33, 88-95.

Huang, S. N., Groh, V., Beaudoin, J. G., Dauphinee, W. D., Guttmann, R. D., Morehouse, D. D., Aronoff, A., and Gault, H. (1974). A study of the relationship of virus-like particles and Australia antigen in liver. Human Pathology, 5, 209-222.

Magnius, L. O., and Espmark, J. A. (1972). New specificities in Australia antigen positive sera distinct from the Le Bouvier determinants. Journal of Immunology, 109, 1017-1021.

Magnius, L. O., Lindholm, A., Lundin, P., and Iwarson, S. (1975). A new antigen-antibody system: clinical significance in long-term carriers of hepatitis B surface antigen. Journal of the American Medical Association, 231, 356-359.

Marx, J. L. (1975). Actin and myosin: role in non-muscle cells. Science, 189, 34.

Nielsen, J. O., Dietrichson, O., and Juhl, E. (1974). Incidence and meaning of the " $e$ " determinant among hepatitis-B-antigen positive patients with acute and chronic liver diseases. Lancet, 2, 913-915.

Nowoslawski, A., Krawczynski, K., Brzosko, W. J., and Madaliński, K. (1972). Tissue localization of Australia antigen immune complexes in acute and chronic hepatitis and liver cirrhosis. American Journal of Pathology, 68, 31-56.

Phillips, M., and Oda, M. (1974). The bile canalicular web (Abstract). Federation Proceedings, 33, 626.

Ray, M. B. (1978). On hepatitis B virus antigen in tissues. Thesis, K. U. L., Leuven.

Ray, M. B., Desmet, V. J., Bradburne, A. F., Desmyter, J., Fevery, J., and De Groote, J. (1976b). Differential distribution of hepatitis B surface antigen and hepatitis B core antigen in the liver of hepatitis B patients. Gastroenterology, 71, 462-469.

Ray, M. B., Desmet, V. J., Fevery, J., De Groote, J., Bradburne, A. F., and Desmyter, J. (1976a). Distribution patterns of hepatitis B surface antigen (HBsAg) in the liver of hepatitis patients. Journal of Clinical Pathology, 29, 94-100.

Rizzetto, M., Bonino, F., Crivelli, O., Canese, M. G., and Verme, G. (1976). Complement fixing hepatitis B core antigen immune complexes in the liver of patients with HBs antigen positive chronic disease. Gut, 17, 837-843.

Sarno, E., Gerber, M. A., and Vernace, S. (1975). Complement fixing immune complexes in the hepatocytic nuclei of patients with hepatitis $B$ antigen 
positive chronic hepatitis (Abstract). Gastroenterology, 69, 862.

Shikata, T. (1973). Australia antigen in liver tissue-an immunofluorescent and immunoelectron microscopic study. Japan Journal of Experimental Medicine, 43, 231-245.

Stein, O., Fainaru, M., and Stein, Y. (1972). Visualization of virus-like particles in endoplasmic reticulum of hepatocytes of Australia antigen carriers. Laboratory Investigation, 26, 262-269.

Trepo, C., Vitvitski, L., Neurath, R., Hashimoto, N., Schaefer, R., Nemoz, G., and Prince, A. M. (1976).
Detection of $e$ antigen by immunofluorescence in cytoplasm of hepatocytes of HBsAg carriers (Abstract). Lancet, 1, 486.

Yamada, G., and Nakane, P. K. (1977). Hepatitis B core and surface antigens in liver tissue. Laboratory Investigation, 36, 649-659.

Requests for reprints to: Dr Rita De Vos, Academisch Ziekenhuis Sint Rafaël, Laboratorium voor Histocytochemie, Minderbroedersstraat 12, B-3000 Leuven, Belgium. 